\title{
Research on electrodes and electrolyte active substances of metal modified battery
}

\author{
Hongmin Gao, Jiansheng Wang ${ }^{\mathrm{a}}$ and Huanyao Qin \\ School of Information and Electronics, Beijing Institute of Technology, 100081, Beijing, China
}

\begin{abstract}
Based on the principle of chemical power source primary battery, the material selections of the positive and negative electrodes of the metal modified battery were studied. The selection methods of the positive and negative electrodes materials and the modification and correction of the copper thin and aluminum thin are discussed. The characteristics of the electrolyte materials or the active substances were given. The research and testing results show that metal modified batteries are better than other rechargeable battery in energy storage, circulation use times, weight, volume, and safety. Its charging time is very short and discharge is slow. The service life is up to six years at electricity generation and discharge times, and it is more suitable for the motor in the driving voltage of $220 \mathrm{~V}$ and the normal driving power current is above $80 \mathrm{~A}$. The electric vehicle is equipped with $80 \mathrm{~kg}$ metal modified battery, which can be continuous drive for more than $450 \mathrm{~km}$ and ensure the dynamic performance of the vehicles. The metal modified battery has higher voltage, higher energy density, longer cycle use life, faster electric energy regeneration rate and excellent environmental compatibility than lithium ion batteries, and its weight is lighter than lead-acid batteries, graphene battery. So the Metal modified battery can be widely used as power supply in all kinds of electric vehicles and electronic equipments.
\end{abstract}

Keywords: battery electrode; oxide electrolyte; active substance; metal modified battery; battery membrane; rechargeable battery; high voltage activation; electric vehicle.

\section{Introduction}

In electric vehicles, battery not only need to provide enough energy for vehicle's, but also need to provide corresponding energy for all kinds of electronic control unit or system in electric vehicles. The capacity size, the voltage magnitude and current intensity of the battery provided are related to the vehicle's dynamic performance, and have influence on people to focus on the endurance mileage of electric vehicles. With electronic equipment, advanced transport facilities, especially EVs and HEVs growing demand for batteries, all kinds of electronic devices and electric vehicles to the requirements of the battery are mainly concentrated in higher energy, higher energy density and longer cycle life as well as the shorter renewable electricity or charging time. Therefore, comprehensive consideration the capacity, volume, weight, voltage, current, resistance of battery, it is necessary to study a new type energy batteries, ensure the electric vehicle has a good dynamic performance at runtime, this is also the project required the necessary technical indicators or

${ }^{a}$ Corresponding author: taoloveit@163.com 
parameters. This project will research, design, and realize a kind of new chemical battery - metal modified battery. Metal modified battery is a kind of new energy battery that has many good parameters, and can satisfactory the power battery performance requirements. The battery has many advantages, such as rapid activate electricity, large battery capacity, small volume, light weight, no pollution, battery materials can be recycled and easy maintenance etc. Equipping monomer battery can be used for everyday applications such as lighting, mobile power supply, can also be used for individual carrying, and can realize the power supply for electric vehicles with the power management system [1].

\section{Primary battery principles}

The conditions of the primary battery needs two different kinds of active conductor elements as electrodes, and needs electrolyte solution to connect the two electrodes. The two conductor elements are used as the electrodes can be two different metal conductors, or the one is a metal conductor, the other one is non-metal conductor. Electrode materials need to be immersed in the electrolyte solution, making the two electrodes part of being immersed in the electrolyte solution are connected by electrolyte solution, and constitute a primary battery internal circuit. If the load or open circuit is connected on the other side of the two electrodes, which can form a closed circuit, so that the electronics on the electrodes can move from the negative electrode to the positive electrode through the external circuit. Thus, primary battery and external load together form a closed circuit loop, which is the battery power source to provide power to the load [2].

In the process of external power supply, battery electrolyte solution and electrode materials can spontaneously occur electrochemical reaction, thus forming a positive electrode and a negative electrode. One of the more active metal conductor electrode spontaneous happens oxidation reaction, metal elements lost electrons, valence rise, namely the negative electrode, become a battery cathode, and another relatively inert metal or nonmetal conductor electrode, such as graphite, get the electrons, electrons transfer to cation of electrode position, thus making cationic combine electronics, valence reduce, happens reduction reaction, namely the positive electrode, become a battery anode. For example: primary battery composed of zinc, copper, dilute sulphuric acid as shown in Figure 1.

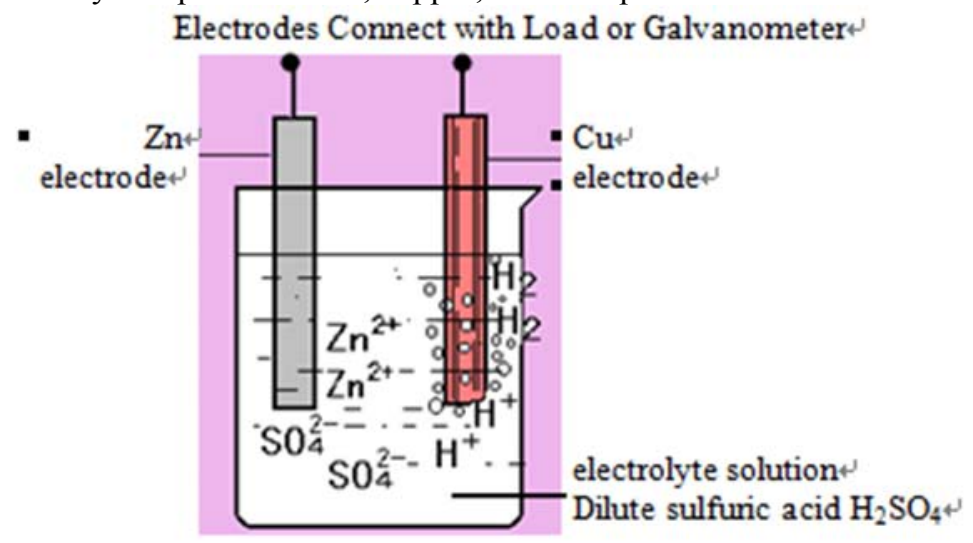

Figure 1. Primary battery composition principles.

One of the more active metal zinc electrode conductor spontaneous happens oxidation reaction, which formed the cathode zinc,

$$
\mathrm{Zn}-2 \mathrm{e}^{-}=\mathrm{Zn}^{2+}
$$

Zn loses electronics, valence rise, be oxidized, happens the oxidation reaction. Another relatively inert metals copper conductor electrode, namely the anode copper, the cathode zinc lost electrons 
move to the copper electrode through the external circuit, copper electrode pass electrons to the $\mathrm{H}^{+}$ nearby the electrode position,

$$
2 \mathrm{H}^{+}+2 \mathrm{e}^{-}=\mathrm{H} 2 \uparrow
$$

$\mathrm{H}^{+}$gets electronic, valence fall, be reduced, occurs reduction reaction. Therefore the total primary battery reaction equations is:

$$
\mathrm{Zn}+2 \mathrm{H}^{+}=\mathrm{Z}^{2+}+\mathrm{H} 2 \uparrow
$$

Therefore, the electrolyte solution and electrode material of the primary battery can achieve the function of providing energy for external circuit through the spontaneous oxidation-reduction reaction. The electrochemical reaction can produce electricity energy. Because the essence of oxidationreduction reaction is electrons transfer, and the result of primary battery reaction can produce current in the closed circuit loop, so the essence of the primary battery reaction is spontaneous oxidationreduction reaction. Under the same conditions, the ability of primary battery output power is depends on oxidation-reduction ability and electrochemical reaction rate of the primary battery reactants. At the same time, the battery electrode reaction speed is related to the size and the shape of electrode surface area, namely the surface area contacted between the electrode and the electrolyte solution is greater, the electrochemical reaction rate is bigger, and the battery has a bigger current. In order to increase the external circuit current by the battery provided, we hope the contact area of electrode and the electrolyte solution (or active substances) is the larger the better. Consequently electrode is designed for thin sheet, which different from the traditional cylindrical bar, even the electrode is designed for the mesh or powder film, greatly increase the reaction area. Such as the cathode using zinc by using film zinc powder instead, making a doubling of reaction area, making the battery discharge current increase significantly, thus increase the battery power supply current.

\section{Metal modified battery material and key technology}

According to the composition and the working principle of the primary battery, the new energy battery is composed of positive electrode, negative electrode and electrolyte solution in this research and design project. Because of the battery research and design using a metal modification technology, therefore it is said the battery is metal modified battery. The battery is mainly composed of positive electrode, negative electrode and electrolyte, where adopts copper thin as the negative electrode, aluminum thin as the positive electrode and the electrolyte is made of powdered materials as shown in Fig.2. Battery does not use electrolyte solution, and the powdered material is called active substances or self-closing separator so that the metal modified battery uses the self-closing separator to replace the electrolyte solution in the battery. As a result, no electrolyte solution is used in the electrochemical reaction of the metal modified battery, and hydrogen or other gases is not produced in the working process of the battery, and the use of the battery is safer and more convenient.

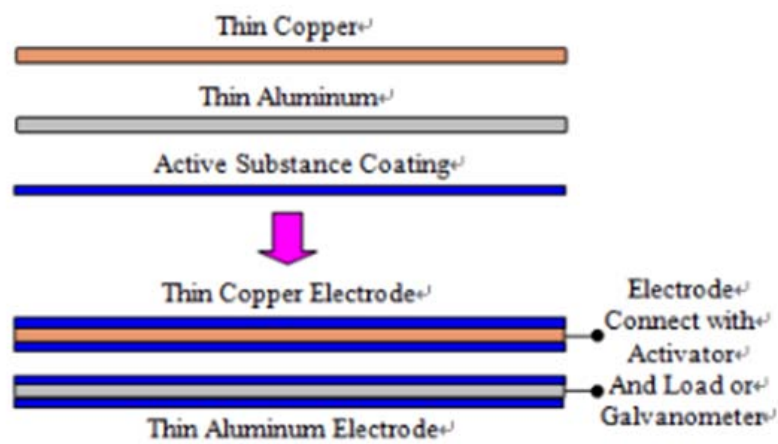

Figure 2. Metal modified battery composition principle. 
Although there is no electrolyte solution, but this does not mean that there is no electrolyte in the battery, the active substances or the self-closing separator is a function of the electrolyte. Under certain conditions, electrolyte ions can shake again between the positive electrode and negative electrode in the metal modified battery, so the metal modified battery is a rocking chair batteries too. Due to the existence of the self-closing separator, the positive and negative ions in the battery can not be returned to the original state or position, so the positive and negative ions are gathered at the corresponding electrodes to form a voltage. Only by discharging for the external circuit loop, the voltage and the energy between the positive electrode and negative electrode can be released, so that the function of the battery can be realized.

\subsection{Electrode material of metal modified battery}

Metal modified batteries is the same as other batteries with positive and negative electrode, where the negative electrode is made of copper thin material. When the battery work thin copper losses of electrons. The positive electrode is made of thin aluminum material. When the battery is working, the aluminum thin gets electrons. The metal modified battery's electrode material and the active coating substances preparation can usually be produce in special temperature and humidity conditions. Although the actual situation of the environment temperature and humidity will vary in different application areas, but the impact is not great for the metal modified secondary battery, and it is still need further discussion when the battery in extreme environments.

In the selection of electrode materials, the quality characteristics of copper thin and aluminum thin as electrode materials are required. Due to the electrode material of the thin copper and the thin aluminum are not necessarily the pure copper and aluminum, and the actual raw material is also very difficult to achieve the purity of pure copper and aluminum requirements, the thin copper and the thin aluminum always more or less contains a number of some other elements or impurities. In order to make clear and definite the characteristics of the electrode material, the content of other impurities or trace elements in the electrode should be clearly defined. The content of impurities or trace elements in copper and aluminum materials would affect the working characteristics of the electrode and the material properties of the post spray active substances, which is not conducive to the cultivation of the active substances and the function. In addition, in the selection of raw materials, copper, aluminum materials have a lot of different types. For consideration of plastic processing, conformal forming, it is the first purposes of metal modification that improve electrode material properties and getting good ductility. For preparation of electrolyte or active substances, it is the second purposes of metal modification[3].

Due to the copper and the aluminum as the electrode material to participate in the electrochemical reaction, one of the important prerequisites of good consistency for batteries is the good consistency of the electrode material properties. Therefore, the characteristics of thin copper, thin aluminum, and the quality control standard index of materials, such as the content of impurities and trace elements and other parameters must be research. The containing of variety trace elements in copper thin, aluminum thin must be analyzed and identified in order to then a further correction. According to the material composition and characteristics of the raw material, adding appropriate proportion of the correction elements, the copper thin, aluminum thin material can be modified, and finally to meet the physical and chemical characteristics of the requirements of the electrode materials. Research showed that the content requirements of other trace elements in copper thin, aluminum thin of electrode materials in the metal modified battery are relatively relaxed. In accordance with the specific circumstances of the trace elements add the modified elements such as Ag and $\mathrm{C}$ and so on into the copper thin, aluminum thin can be realized and fixed the material type. The conductivity of the electrode surface was improved or decreased by the method of surface penetration and internal doping as shown in Table 1 . The conductivity and ductility of the electrodes were measured by using unit cross-sectional area and unit length material. By adding a variety of elements, mainly consisting of Ag element silver and $\mathrm{C}$ element carbon, the charge concentration and positive ion and negative ion 
adsorption capacity of the battery were tested to evaluate the conductivity and ductility of the electrodes.

Table 1. The correction elements and the characteristics of the electrodes.

\begin{tabular}{|c|c|c|c|}
\hline raw material & $\begin{array}{c}\text { modified elements } \\
\text { (Addition amount } \mathrm{mg})\end{array}$ & $\begin{array}{c}\text { ductility } \\
\text { (Original Length } \\
10 \mathrm{~mm} \text {, Unit mm) }\end{array}$ & $\begin{array}{c}\text { electrical conductivity } \\
\text { (Original Cross-sectional } \\
\text { Area 1mm2, Unit S/m) }\end{array}$ \\
\hline $99.9 \%$ thin copper & $\mathrm{Ag}(2 \mathrm{mg} / \mathrm{mm} 2)$ & $15.9 \mathrm{~mm}$ & $5.79 \times 10^{7}$ \\
\hline $95.6 \%$ thin copper & $\mathrm{Ag}(2 \mathrm{mg} / \mathrm{mm} 2)$ & $14.5 \mathrm{~mm}$ & $5.83 \times 10^{7}$ \\
\hline $93.6 \%$ thin copper & $\mathrm{Ag}(2 \mathrm{mg} / \mathrm{mm} 2)$ & $12.7 \mathrm{~mm}$ & $5.85 \times 10^{7}$ \\
\hline $99.9 \%$ thin aluminum & $\mathrm{C}(2 \mathrm{mg} / \mathrm{mm} 2)$ & $15.8 \mathrm{~mm}$ & $3.68 \times 10^{7}$ \\
\hline $98.7 \%$ thin aluminum & $\mathrm{Zn}(2 \mathrm{mg} / \mathrm{mm} 2)$ & $12.6 \mathrm{~mm}$ & $2.58 \times 10^{7}$ \\
\hline $96.2 \%$ thin aluminum & $\mathrm{Zn}(1 \mathrm{mg} / \mathrm{mm} 2), \mathrm{C}(1 \mathrm{mg} / \mathrm{mm} 2)$ & $13.8 \mathrm{~mm}$ & $4.13 \times 10^{7}$ \\
\hline
\end{tabular}

\subsection{Characteristics of active substances and the special energy storage method}

No electrolyte solution in the metal modified battery, instead of electrolyte solution is active substances. The active substances sprayed on the surface of the electrode materials, namely in copper thin, aluminum thin surface spraying active substances are actually in metal electrode surface coated with electrolyte powder. The active substances are a kind of special material between conductor and insulator. Because of the special characteristics of the active substances under different voltage conditions, the spraying active substances are called the self-closing separator. The metal powder and other necessary special materials doped synthesized in order to cultivate the active substances. The subject of preparation of active substances is a nano particles. The crystallization of the nano particles is very good, not easy to be oxidized. Anisotropy is one of the basic properties of the single crystal, the different surface with different atomic density, exhibit different properties, so for the same kind of material, control the morphology and exposed on the surface of its physical and chemical properties can be regulated. For the nano materials, not only the morphology of the nano materials have influence on the properties, the nano particle size and the size of distribution also have an impact on the properties of nano materials[4]. The nano type semiconductor material provides the conditions for forming the battery positive, negative electrode.

The electrochemical reaction of the first battery is irreversible, that is to say, the journey of the chemical energy turns into electrical energy can only go black, the power is exhausted, the battery is useless. For the secondary battery, such as ordinary rechargeable battery, the battery charge is use the suitable current to charge into the battery gradually. The rechargeable battery adopts reversible electrochemical reaction. As long as the applied voltage, change the direction of electrons flow (the current flow from the positive electrode to the negative electrode), the electrodes of the battery will occur the chemical reaction which is in the opposite direction of the discharge, and finally the secondary battery will be refilled with power energy. The subject of the study of metal modified battery is a secondary chemical battery, but it is not the charging for aggregating power to allow the battery to be full of energy, instead of using the electric activation. This is also due to the battery using a special electrolyte active substances and which can achieved a self-closing separator function in certain conditions.

The Metal modified battery is use a special activation electrical energy regeneration method and power energy storage mode. The activation is the method of loading the appropriate high voltage to the metal modified battery, which is not enough to use as the electric power. Metal modified battery's 
activation is mainly loading of high voltage through the battery positive electrode and negative electrode, and the active substances of the battery are actived in an extremely short period [5]. Because the performance of coating active substances on the electrode surface can keep the positive electrode and negative electrode retained a higher potential, the resistance is still keep infinite inside the battery. So the active substances are called the self-closing separator. Metal modified batteries can generate electricity by activating. Due to the high potential exists between the positive electrode and the negative electrode, internal battery could not eliminate high potential, it is this feature that makes the metal modified battery can provide power to the load of external circuit. Consequently, the activation capacity and the actived time for activing the self-closing separator of the metal modified battery are related to the physical and chemical properties of the active substances and the active voltage level as shown in Table 2 . The metal modified battery has a strong ability to regenerate power.

Table 2 . The activation capacity and the actived time of the metal modified battery.

\begin{tabular}{|c|c|c|c|}
\hline $\begin{array}{c}\text { Active Substances } \\
\text { (particle Size Unit Mesh) }\end{array}$ & $\begin{array}{c}\text { Active Voltage Level } \\
\text { (Unit V) }\end{array}$ & $\begin{array}{c}\text { Activation Capacity } \\
\text { (Unit Ah) }\end{array}$ & $\begin{array}{c}\text { Actived Time } \\
\text { (Unit s) }\end{array}$ \\
\hline \multirow{3}{*}{200} & 110 & 1.7 & 3078 \\
\cline { 2 - 4 } & 220 & 2.1 & 2990 \\
\cline { 2 - 4 } & 380 & 3.6 & 2540 \\
\hline \multirow{3}{*}{300} & 110 & 2.3 & 2856 \\
\cline { 2 - 4 } & 220 & 3.1 & 2805 \\
\hline \multirow{3}{*}{400} & 380 & 5.2 & 2125 \\
\cline { 2 - 4 } & 110 & 2.4 & 2932 \\
\cline { 2 - 4 } & 220 & 3.1 & 2830 \\
\hline \multirow{3}{*}{500} & 380 & 5.3 & 1953 \\
\cline { 2 - 4 } & 110 & 2.4 & 2979 \\
\cline { 2 - 4 } & 220 & 3.2 & 2890 \\
\hline \multirow{3}{*}{} & 380 & 5.8 & 1862 \\
\hline
\end{tabular}

\section{Metal modified battery pack distribution test}

\subsection{Metal modified battery pack practical application test}

1 basic metal modified battery voltage is $2 \mathrm{~V}$. 2 basic metal modified battery in series as monomer battery voltage is $4 \mathrm{~V} .3$ monomer series can obtain $12 \mathrm{~V}$ battery pack, the rest can be done in the same manner battery pack can provide a bigger battery voltage. Three metal modified monomer batteries in series can get $12 \mathrm{~V}$ battery pack, which can obtain the maximum current up to $40 \mathrm{~A}$ by the test. Compared with the classic battery in rate of discharge in test, lead-acid batteries discharge intensity is better than metal modified battery, but metal modified battery is better than lithium battery. It is four $12 \mathrm{~V}$ metal modified battery packs are composed in series that get $48 \mathrm{~V}$ battery. Then every five $48 \mathrm{~V}$ batteries are connected in parallel is called $48 \mathrm{~V}$ power battery array pack for electric vehicles. The five $48 \mathrm{~V}$ power battery array packs are connected in series processing can get $240 \mathrm{~V}$ metal modified power battery pack. The $240 \mathrm{~V}$ power battery array packs can provide power for the electric vehicles, and supply the current above $80 \mathrm{~A}$. It uses AC active voltage. The active voltage level is about $380 \mathrm{~V}$, and the actived time is less than 10 minutes. The metal modified power battery pack is more suitable in the driving voltage of $220 \mathrm{~V}$ motor. In the actual application of the test, the electric vehicles can continue travel for $467.3 \mathrm{~km}$ when it is equipped with the $80 \mathrm{~kg}, 240 \mathrm{~V}$ power metal modified battery 
pack. The battery pack provides normal driving power capacity of about $412.55 \mathrm{Ah}$ (or $100.8 \mathrm{kwh}$ ), and the car's running speed is more than $110 \mathrm{~km} / \mathrm{h}$.

\subsection{Metal modified battery pack activation}

Metal modified battery activation system can be used for monomer $4 \mathrm{~V}$ battery, $12 \mathrm{~V}$ batteries and special metal modified battery of the electric vehicle. Two sets of battery power supply cooperate work can realize the internal activation. A set of metal modified battery pack, plus a set of small capacity metal modified battery pack, and the smaller secondary battery can be used to boost the activation of large battery through the inverter circuits or devices [6]. Metal modified battery pack has not memory. There is no liquid substance in the battery, so it does not produce the gas (e.g. hydrogen) when it works, even thrown into the fire it will not explode, so use it will be safe. This battery is very suitable for use in electric vehicles, also can be used as energy storage battery. Metal modified battery is easy to be designed into various shapes, the cost is low, the activation will generate electricity, and easy to realize long-distance mileage.

\section{Conclusions}

Compared with the classic mainstream technology products such as lead-acid batteries, lithium batteries, phosphoric acid iron lithium battery, the metal modified battery has sufficient energy, recycle times reach requirements, light weight, small volume, good safety performance, does not require high and low temperature compensation, almost from the influence of environment temperature, charging time is very short, slow discharge. Active substances can not fall from positive electrode and the negative electrode. The metal modified battery has electricity generation and discharge times, and the service life for about six or seven years, renewable electricity in a very short period of time. The experimental study and test results show that the metal modified battery is more suitable in the driving voltage of $220 \mathrm{~V}$ motor. The battery provides normal driving power or current is up to $80 \mathrm{~A}$, suffice to ensure that the dynamic performance of the vehicles. The electric vehicles can continue travel for more than $450 \mathrm{~km}$ when it is equipped with $80 \mathrm{~kg}$ metal modified battery. The metal modified battery has higher voltage, higher energy density, longer cycle use life, faster electric energy regeneration rate and excellent environmental compatibility than lithium ion batteries, so that the metal modified battery has more advantage than the lithium ion battery, lighter than lead-acid batteries, graphene battery weight. The metal modified battery can be widely used in a variety of handheld electronic device and as power supply for electric vehicles. Therefore, it is expected to be the most important and most widely used secondary battery in twenty-first Century.

\section{References}

1. Chun-yang Liu. Quick Charging System for Electric Vehicle [J]. Electrical World, 55(10): 52 (2014).

2. Gao-jun Wang. Exploration of New Rchargeable Chemical Power Source [D]. Fudan University, April 2008: 4.

3. Ying Yu, Fei-peng Du. Progress of Research on Preparation Methods of Nano-Cuprous Oxide [J]. Chemistry Online, 67(1): 1-6 (2004).

4. Ming-zhen Wei, Jian-zhen Huo, Ning Lun, Xi-cheng Ma, Shu-lin Wen. A Novel Semiconductor Photocatalyst-Nano Cuprous Oxide [J]. Materials Review, 21(6): 130-133(2007).

5. Hui-fang $\mathrm{Wu}$. Morphology and Size Control of Silver oxide Silver and Cuprous oxide Micro/Nano- Particles [D]. Xiamen University, May 2007.

6. Xin-ping Ding, Cheng-hui Zhang, Bi-cui Xue, Min Zhang. A Novel High Voltage Ratio SingleStage Inverter with Buck-Boost Ability [J]. Transactions of China Electrotechnical Society, 29(10): 73-79(2014). 